\title{
Surface Tension and Its Temperature Coefficient of Molten Tin Determined with the Sessile Drop Method at Different Oxygen Partial Pressures
}

\author{
Zhang Fu Yuan, ${ }^{*},{ }^{1}$ Kusuhiro Mukai, $\ddagger$ Katsuhiko Takagi, $§$ Masahiko Ohtaka,§ Wen Lai Huang,* and Qiu Sheng Liu $\dagger$ \\ * Multi-Phase Reaction Laboratory, Institute of Process Engineering, Chinese Academy of Sciences, Beijing 100080, People’s Republic of China; †National \\ Microgravity Laboratory of China, Institute of Mechanics, Chinese Academy of Sciences, Beijing 100080, People’s Republic of China; $\ddagger$ Department \\ of Materials Science and Engineering, Faculty of Engineering, Kyushu Institute of Technology, Kitakyushu 804-8550, Japan; \\ and §National Space Development Agency of Japan, Tsukuba 305-8505, Japan
}

Received April 8, 2002; accepted July 9, 2002

\begin{abstract}
The surface tension of molten tin has been determined by the sessile drop method at temperatures ranging from 523 to $1033 \mathrm{~K}$ and in the oxygen partial pressure $\left(P_{\mathrm{O}_{2}}\right)$ range from $2.85 \times 10^{-19}$ to $8.56 \times 10^{-6} \mathrm{MPa}$, and its dependence on temperature and oxygen partial pressure has been analyzed. At $P_{\mathrm{O}_{2}}=2.85 \times 10^{-19}$ and $1.06 \times 10^{-15} \mathrm{MPa}$, the surface tension decreases linearly with the increase of temperature and its temperature coefficients are -0.151 and $-0.094 \mathrm{mN} \mathrm{m}^{-1} \mathrm{~K}^{-1}$, respectively. However, at high $P_{\mathrm{O}_{2}}(3.17 \times$ $\left.10^{-10}, 8.56 \times 10^{-6} \mathrm{MPa}\right)$, the surface tension increases with the temperature near the melting point $(505 \mathrm{~K})$ and decreases above $723 \mathrm{~K}$. The surface tension decrease with increasing $P_{\mathrm{O}_{2}}$ is much larger near the melting point than at temperatures above $823 \mathrm{~K}$. The contact angle between the molten tin and the alumina substrate is $158-173^{\circ}$, and the wettability is poor. (c) 2002 Elsevier Science (USA)

Key Words: molten tin; surface tension; temperature coefficient; oxygen potential; sessile drop method.
\end{abstract}

\section{INTRODUCTION}

The dependence of the surface tension of molten tin on temperature and oxygen partial pressure is known as a complicated liquid action, and the precisely measured values are required for the elucidation of the Marangoni convection of molten tin.

The convection of molten tin consists of Marangoni convection resulting from the surface tension gradient and natural convection which generally results from the density difference of molten tin, and the actual condition of Marangoni convection is not clear. One of the main reasons is that the surface tension of molten tin which is indispensable has not been measured correctly, especially the temperature and oxygen dependence. The reported temperature-dependence data have been measured with unknown oxygen partial pressure, and there exists a large difference among those values (1-24).

\footnotetext{
${ }^{1}$ To whom correspondence should be addressed at Institute of Process Engineering, Chinese Academy of Sciences, Zhong Guan Cun, Haidian District, P.O. Box 353, Beijing 100080, People's Republic of China. Fax: 86-1062527440. E-mail: yuanzhf@home.ipe.ac.cn.
}

The atmosphere control is thus necessary to obtain accurately the oxygen and temperature dependence of the surface tension of molten tin. The affinity of tin with oxygen is very large, and the balanced oxygen partial pressure $P_{\mathrm{O}_{2}}$, sat with $\mathrm{SnO}_{2}$ (s) around molten tin near the melting point $(505 \mathrm{~K})$ is as low as $10^{-51} \mathrm{MPa}$. Therefore, the atmosphere control in the measurement system is very difficult.

In the present work, the surface tension of molten tin is measured with the sessile drop method in precisely controlled oxygen partial pressure, and the effects of oxygen partial pressure and temperature are both investigated.

\section{EXPERIMENTAL}

\subsection{Apparatus}

Figure 1 illustrates the schematic diagram of the surface tension measurement equipment of molten tin by the sessile drop method. The system consists of a furnace, a gas refining equipment, an oxygen partial pressure measuring sensor, drop photography equipment, and a digitizer and computer analysis system. The Kanthal line $(67 \mathrm{Fe}, 25 \mathrm{Cr}, 5 \mathrm{Al}, 3 \mathrm{Co})$ is used in the resistance furnace, and the highest temperature is $1173 \mathrm{~K}$.

The quartz pipe (inner diameter, $30 \mathrm{~mm}$; outer diameter, $34 \mathrm{~mm}$; length, $560 \mathrm{~mm}$ ) is sealed with quartz caps at both ends. With the adoption of the oil rotation vacuum pump, the reaction pipe can reach $10^{-3} \mathrm{~Pa}$ within $0.5 \mathrm{~h}$ at room temperature. The tip of the J-0.4th class $(\mathrm{Fe}-\mathrm{CuNi})$ thermocouple in an alumina protection pipe between quartz pipes is located directly under the alumina substrate and tin drop. The temperature difference between the thermocouple position and the tin drop position is neglectable. The Ar gas (purity of $99.999 \%, \mathrm{O}_{2}<0.2 \mathrm{ppm}$ ) is deoxidized with magnesium chips heated at $873 \mathrm{~K}$, and $P_{\mathrm{O}_{2}}$ can be controlled between $10^{-20}$ and $10^{-5} \mathrm{MPa}$ by changing the temperature of the magnesium furnace.

\subsection{Materials and Procedure}

The cylindrical sample $(\phi 3.5 \times 3.5 \mathrm{~mm}$, about $0.3 \mathrm{~g}$; purity, 99.999 mass\%) of tin on a high-purity alumina substrate 


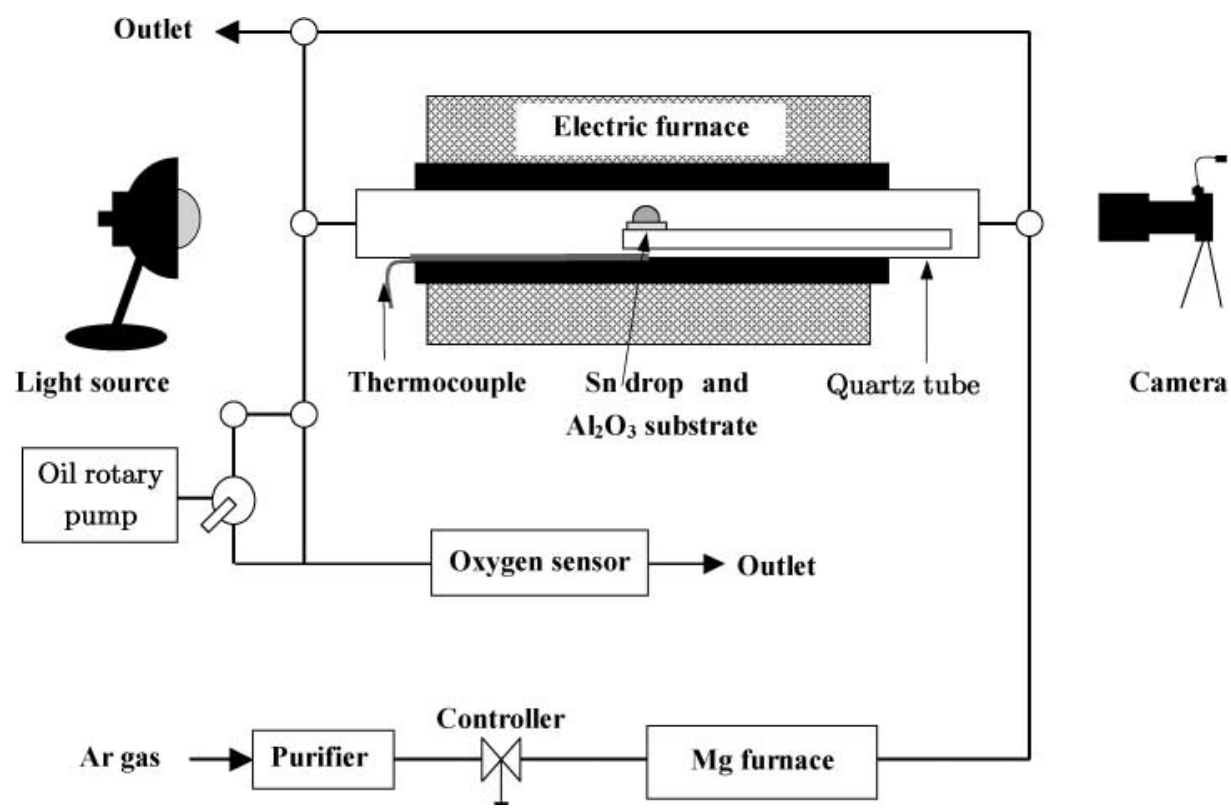

FIG. 1. Schematic diagram of the experimental apparatus.

(99.95 mass $\% \mathrm{Al}_{2} \mathrm{O}_{3}$ ) was put into the quartz pipe and made horizontal by two water levels. After the furnace was sealed and evacuated, refined argon gas was passed through (the flux was $120 \mathrm{~mL} / \mathrm{min}$ ). When the furnace reached scheduled temperature, the argon gas flux was maintained at $80 \mathrm{~mL} / \mathrm{min}$. Oxygen partial pressure in the atmosphere was measured by a solid-electrolyte oxygen sensor. Photographs of the droplet were taken at certain intervals. As shown in Fig. 1, the photography system including telephoto lens and bellows was installed on the observation window at one end of the quartz pipe. The mini-copy film HRII negative was used, which carried out photography development on printing paper of large size (VR4, $130 \times 180 \mathrm{~mm}$ ), and the drop image was evaluated with the digitizer. The magnification in the present work determined by the photograph of a standard steel ball ( $5 \mathrm{~mm}$ in diameter) is to be 17.86 , and no image distortion is observed.

In the sessile drop method, the surface tension and contact angle can be obtained from the droplet contour, and the density is required for calculation. In the present work, the algorithm proposed by Rotenberg et al. (25) is adopted, and the measurement errors for surface tension and contact angle are \pm 2 and $\pm 0.5 \%$, respectively (26). The adopted density value is $\rho / \mathrm{Mg} \mathrm{m}^{-3}=$ $1 / V=\left(0.14315+14.9 \times 10^{-6}\left(T-T_{\mathrm{m}}\right)\right)^{-1}(27)$.

\subsection{Measurement of the Oxygen Partial Pressure}

The oxygen sensor used in the present work is an oxygen content battery (28), in which $\mathrm{CaO} \cdot \mathrm{ZrO}_{2}$ (stabilized $\mathrm{ZrO}_{2}$, $11 \mathrm{mo} 1 \% \mathrm{CaO}$ ) serves as the conductor of oxygen ion, and the mixed powder (molar ratio $1: 1$ ) of $\mathrm{Ni}$ and $\mathrm{NiO}$ is used as a reference electrode. Electromotive power $E$ caused by the difference of oxygen partial pressure between the reference electrode
$P_{\mathrm{O}_{2}(\mathrm{Ni}-\mathrm{NiO})}$ (equilibrium oxygen partial pressure of $\mathrm{Ni}$ and $\mathrm{NiO}$ ), and the measured gas (action pole side) can be expressed as follows using the Nernst formula:

$$
E=-(R T /(4 F)) \ln \left(P_{\mathrm{O}_{2}} / P_{\mathrm{O}_{2}(\mathrm{Ni}-\mathrm{NiO})}\right)
$$

Here $E$ is the electromotive power of the battery, $R$ is the gas constant, and $T$ and $F$ are the battery temperature and the Faraday constant, respectively. The equilibrium oxygen partial pressure of $\mathrm{Ni}$ and $\mathrm{NiO}$ is given by

$$
P_{\mathrm{O}_{2}(\mathrm{Ni}-\mathrm{NiO})}=\exp \left(2 \Delta G_{1}^{\mathrm{o}} /(R T)\right),
$$

where $\Delta G_{1}^{\mathrm{o}}$ is the standard free energy of formation for $\mathrm{NiO}$ (29) is written as

$$
\Delta G_{1}^{\mathrm{o}}=-232870+83.23 T(\mathrm{~J} / \mathrm{mol}) .
$$

Therefore the oxygen partial pressure can be expressed with the following, drawn from Eqs. [1] and [2]:

$$
P_{\mathrm{O}_{2}}=\exp \left(\left(4 E F+2 \Delta G_{1}^{\mathrm{o}}\right) /(R T)\right) .
$$

Platinum thread is used as the outside electrode of the manufactured oxygen sensor and nickel line as the inside electrode (29). In order to reduce the measurement error caused by the formation of the oxygen concentration boundary layer in the solid electrolyte-gaseous phase interface, gas was prepared in the end of the quartz pipe and sprayed on the joint of the platinum thread and solid electrolyte. When the oxygen sensor was calibrated using air and argon standard gas of 2 vol\% oxygen, the error was $0.5-3 \%$, and the error in argon standard gas with an oxygen 
concentration of $1 \mathrm{ppm}$ was $1-5 \%$. Measurement of the oxygen partial pressure in argon gas that enters the furnace $\left(P_{\mathrm{O}_{2}}^{\text {in }}\right)$ or exhausts from the furnace $\left(P_{\mathrm{O}_{2}}^{\text {out }}\right)$ is selected using a three-way cock.

\section{RESULTS AND DISCUSSION}

\subsection{Thermodynamic Analysis of the Gas-Solid Equilibrium of Molten Tin System}

$\mathrm{Sn}$ is very easy to oxidize, and the oxidization generally proceeds by the following reactions.

$$
\begin{aligned}
\mathrm{Sn}(\mathrm{l})+\mathrm{O}_{2}(\mathrm{~g}) & =\mathrm{SnO}_{2}(\mathrm{~s})(T<1800 \mathrm{~K}) ; \\
\Delta G_{5}^{\mathrm{o}} & =-584,090+212.55 T(30)(\mathrm{J} / \mathrm{mol}) ; \\
\mathrm{Sn}(\mathrm{l})+1 / 2 \mathrm{O}_{2}(\mathrm{~g}) & =\mathrm{SnO}(\mathrm{s})(T<1300 \mathrm{~K}) ; \\
\Delta G_{7}^{\mathrm{o}} & =-287,645+101.52 T(30)(\mathrm{J} / \mathrm{mol}) .
\end{aligned}
$$

The solubility of oxygen in molten tin is very small. If the activity values of $\mathrm{Sn}$ and $\mathrm{SnO}_{2}$ are both set as 1, the calculated equilibrium oxygen partial pressure $\left(P_{\mathrm{O}_{2}}\right.$, sat, the saturated oxygen partial pressure) values are shown in Fig. 2. It is found that the saturated oxygen partial pressure equilibrated with $\mathrm{SnO}(\mathrm{s})$, $P_{\mathrm{O}_{2}}, \mathrm{sat}_{(\mathrm{SnO})}$ is almost the same as the value of $P_{\mathrm{O}_{2}}$, sat.

During the surface tension measurement by the sessile drop method, there exist many problems about the droplet, such as its size, its evaporation, oxidization and reaction with the substrate. In the present investigation of tin, its tendency to oxidize near the melting point is a problem. The extreme low $P_{\mathrm{O}_{2}}$, sat below $900 \mathrm{~K}$ shown in Fig. 2 cannot be obtained on the conditions of Ar atmosphere. Therefore, if only thermodynamic calculations are based, preventing oxidization of molten tin near the melting point will be impossible. However, with the temperature

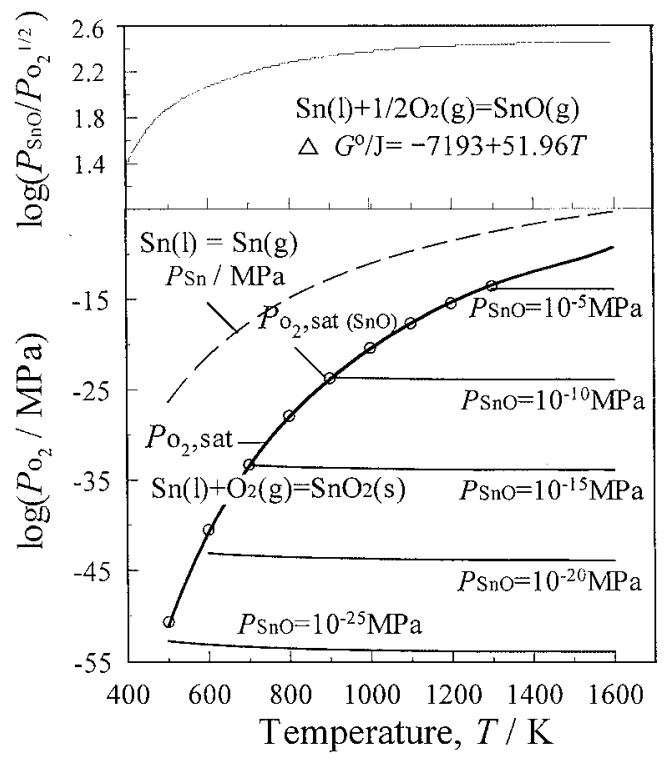

FIG. 2. Equilibrium in the $\mathrm{Sn}(\mathrm{l})-\mathrm{O}_{2}(\mathrm{~g})-\mathrm{SnO}_{2}(\mathrm{~s})-\mathrm{SnO}(\mathrm{g})$ system. increase, oxidization of the tin drop can be practically prevented when the molten metal generates metal steam, which nots as an oxygen-getter pump. $P_{\mathrm{Sn}}$ approaches $P_{\mathrm{SnO}}$ near the melting point, but temperature increase leads it smaller than $P_{\mathrm{SnO}}$, and thus $P_{\mathrm{SnO}}$ and $P_{\mathrm{SnO}} / P_{\mathrm{O}_{2}}^{1 / 2}$ increase remarkably with increasing temperature below $750 \mathrm{~K}$, but increase slightly above that temperature.

Oxygen partial pressure in hydrogen gas atmosphere can be calculated as follows.

$$
\begin{gathered}
2 \mathrm{H}_{2}(\mathrm{~g})+\mathrm{O}_{2}(\mathrm{~g})=2 \mathrm{H}_{2} \mathrm{O}(\mathrm{g}) ; \\
\Delta G_{9}^{\mathrm{o}}=-492,880+19.62 T(31)(\mathrm{J} / \mathrm{mol}) ; \\
=-R T \ln \left(\left(P_{\mathrm{H}_{2} \mathrm{O}} / P_{\mathrm{H}_{2}}\right)^{2}\left(1 / P_{\mathrm{O}_{2}}\right)\right) .
\end{gathered}
$$

Again, if $\left(P_{\mathrm{H}_{2} \mathrm{O}} / P_{\mathrm{H}_{2}}\right)^{2}$ in reaction [9] can be presumed, $P_{\mathrm{O}_{2}}$ can be calculated from Eq. [10].

$P_{\mathrm{O}_{2}}$, sat calculated from thermodynamic data, and $P_{\mathrm{O}_{2}}$ in $\mathrm{H}_{2}$ atmosphere and commercial Ar (purity of 99.999 mass\% or more) atmosphere are shown in Table 1 . Near the melting point, although equilibrium oxygen partial pressure $P_{\mathrm{O}_{2}}$, sat is low, it increases with the temperature increase. The oxygen partial pressure values in $\mathrm{H}_{2}$ atmosphere were measured by Amal et al. (31). Table 1 indicates that $P_{\mathrm{O}_{2}}$ in $\mathrm{H}_{2}$ atmosphere is much smaller than $P_{\mathrm{O}_{2}}$, sat. However, $P_{\mathrm{O}_{2}}$ in Ar atmosphere below $1100 \mathrm{~K}$ (either deoxidized with the magnesium furnace or in a vacuum condition) is higher than $P_{\mathrm{O}_{2}}$, sat. Although in the present measurement, $P_{\mathrm{O}_{2}}$ in Ar atmosphere can be precisely controlled by a magnesium deoxidization furnace (a possible temperature limitation up to $873 \mathrm{~K}$ ), the minimum value is about $10^{-19} \mathrm{MPa}$. Therefore, surface tension measurement of tin in the present work has been performed in conditions of $P_{\mathrm{O}_{2}}$ higher than $P_{\mathrm{O}_{2}}$, sat and temperatures below $1050 \mathrm{~K}$.

In the case of $P_{\mathrm{O}_{2}}<P_{\mathrm{O}_{2}}$, sat, when the oxygen in the gaseous phase is considered to be in equilibrium with that in the molten tin, the oxygen concentration $C_{\underline{o}}$ in the molten tin can be calculated using the standard free energy change $\Delta G_{11}^{\mathrm{o}}$ of reaction [11], and the results are shown in Fig. 3 from Eq. [12]:

$$
\begin{gathered}
1 / 2 \mathrm{O}_{2}(\mathrm{~g}) \leftrightarrow \mathrm{O}_{\mathrm{Sn}} \\
\Delta G_{11}^{\mathrm{o}}=-176300+20.52 T(32)(\mathrm{J} / \mathrm{mol}) \\
=-R T \ln \left(a \mathrm{o} / P_{\mathrm{O}_{2}}^{1 / 2}\right)
\end{gathered}
$$

It is supposed that the system of oxygen in the molten tin is an ideal thin solution, and thus it can be assumed that $a \mathrm{o}=C \underline{\mathrm{o}}$ (at\%).

$C \underline{\mathrm{o}}$, sat shown in Fig. 3 is calculated from $\ln \left(C_{\underline{0}} / \mathrm{at} \%\right)=$

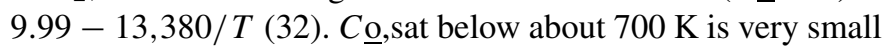
and keeps almost constant. Above $700 \mathrm{~K}$ it increases suddenly.

Figure 3 shows that the oxygen concentration in molten tin with constant $P_{\mathrm{O}_{2}}$ decreases with increasing temperature, and the reduction extent decreases when $P_{\mathrm{O}_{2}}$ becomes low. 
TABLE 1

Oxygen Partial Pressure in Different Atmospheres

\begin{tabular}{|c|c|c|c|c|}
\hline $\begin{array}{l}\text { Temperature } \\
\text { (K) }\end{array}$ & $\begin{array}{l}P_{\mathrm{O}_{2}}, \text { sat } \\
(\mathrm{MPa})\end{array}$ & $\begin{array}{l}P_{\mathrm{O}_{2}} \text { in } \mathrm{H}_{2} \\
(\mathrm{MPa})^{a}\end{array}$ & $\begin{array}{l}P_{\mathrm{O}_{2}} \text { in } \mathrm{Ar} \\
(\mathrm{MPa})^{b}\end{array}$ & $\begin{array}{c}\text { Vac. in } \mathrm{Ar} \\
\left(10^{-6} \mathrm{~Pa}\right)(\mathrm{MPa})\end{array}$ \\
\hline 500 & $1.01 \times 10^{-51}$ & \multirow{4}{*}{$2.2 \times 10^{-52}$ at $573 \mathrm{~K}$} & \multirow{8}{*}{$\begin{array}{c}8.56 \times 10^{-6} \\
\left.\text { (High purity argon: } \mathrm{Ar}>99.999 \%, \mathrm{O}_{2}<0.2 \mathrm{ppm}\right)\end{array}$} & \multirow{8}{*}{$\begin{array}{c}\text { About } 10^{-18} \\
\text { (Calculated from } P_{\mathrm{O}_{2}}=10^{-6} \mathrm{MPa} \\
\text { in } 0.1 \mathrm{MPa} \text { Ar gas }\end{array}$} \\
\hline 600 & $1.57 \times 10^{-41}$ & & & \\
\hline 700 & $3.05 \times 10^{-34}$ & & & \\
\hline 800 & $8.61 \times 10^{-29}$ & & & \\
\hline 900 & $1.45 \times 10^{-24}$ & \multirow[t]{4}{*}{$2.5 \times 10^{-35}$ at $923 \mathrm{~K}$} & & \\
\hline 1000 & $3.39 \times 10^{-21}$ & & & \\
\hline 1100 & $1.90 \times 10^{-18}$ & & & \\
\hline 1200 & $3.63 \times 10^{-16}$ & & & \\
\hline
\end{tabular}

${ }^{a}$ Measured value by Amal et al. (31).

${ }^{b}$ Measured with an oxygen sensor of the solid electrolytes in commercial Ar gas at $1073 \mathrm{~K}$.

\subsection{Measurement Results about the Surface Tension of Molten Tin}

The results, methods, conditions, and the temperature range for the surface tension measurement of molten tin are shown in Table 2 and shown in Figs. 4 and 5. The results can be divided into two groups according to the absolute value of the temperature coefficient of surface tension $|\partial \sigma / \partial T|$. Most results measured in $\mathrm{H}_{2}$ atmosphere belong to the group of small values, while those measured under Ar gas with the maximum bubble pressure method, $\mathrm{N}_{2}, \mathrm{H}_{2}$ atmosphere under vacuum, or decompression constitute the large-value group. That is, the temperature coefficient of surface tension changes with atmosphere. First, under $\mathrm{Ar}$ gas, $\mathrm{N}_{2}, \mathrm{H}_{2}$ gas under vacuum, or decompression, when the purity or the vacuum degree is inadequate, oxidization on the surface of molten metal by the very small quantity of

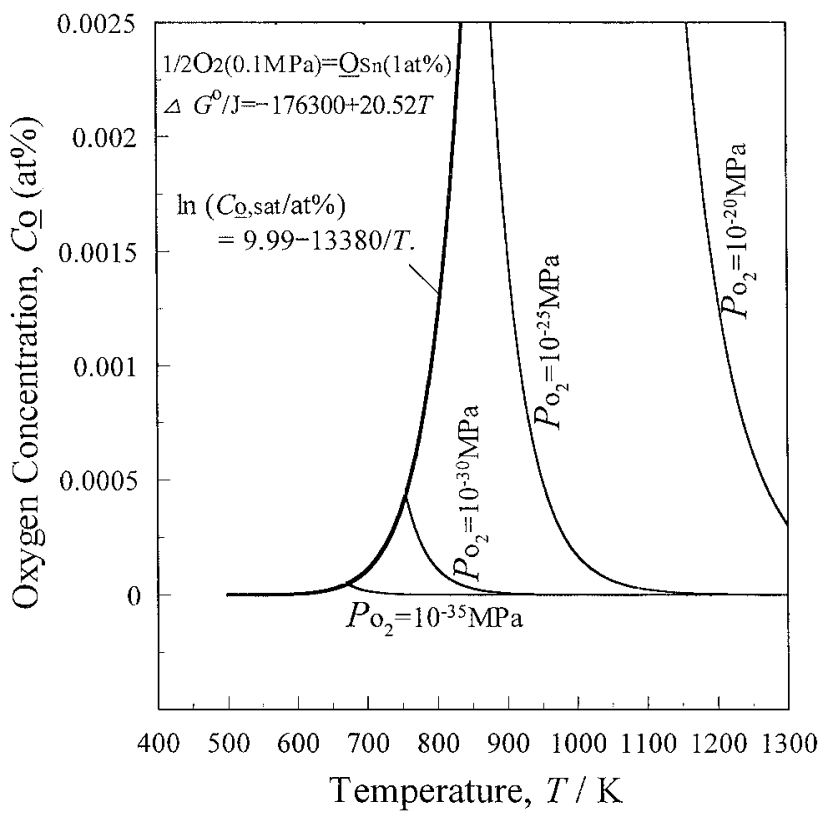

FIG. 3. Evolution of equilibrium oxygen concentration in molten tin with temperature. oxygen in atmosphere might occur. Second, under a vacuum or an evacuated atmosphere, evaporation of the molten metal or its oxides from the surface should be considered.

Goumiri et al. (17) clarified that $\mathrm{SnO}_{2}$ film exists on the surface of tin drop under a vacuum $\left(10^{-7} \mathrm{~Pa}\right)$ by Auger electron spectroscopy (AES). Sangiorgi et al. (19) measured the tin surface tension under the vacuum of $10^{-6} \mathrm{~Pa}(560 \mathrm{~K})$ by the sessile drop method and found that when oxygen was enriched in the surface of tin drop, the surface tension at $560 \mathrm{~K}$ is $535 \mathrm{mN} / \mathrm{m}$, but $598 \mathrm{mN} / \mathrm{m}$ when the surface was clean. $\mathrm{SnO}$ and $\mathrm{SnO}_{2}$ films were also observed to generate on the drop surface with the adoption of AES. Passerone et al. (21) measured the surface tension of tin under the vacuum of $\mathrm{He}+5 \% \mathrm{H}_{2}$ in the temperature range from near the melting point to $1073 \mathrm{~K}$ using the sessile drop method. The results indicated that the surface tension in the $300 \mathrm{~K}$ temperature range above the melting point exhibited

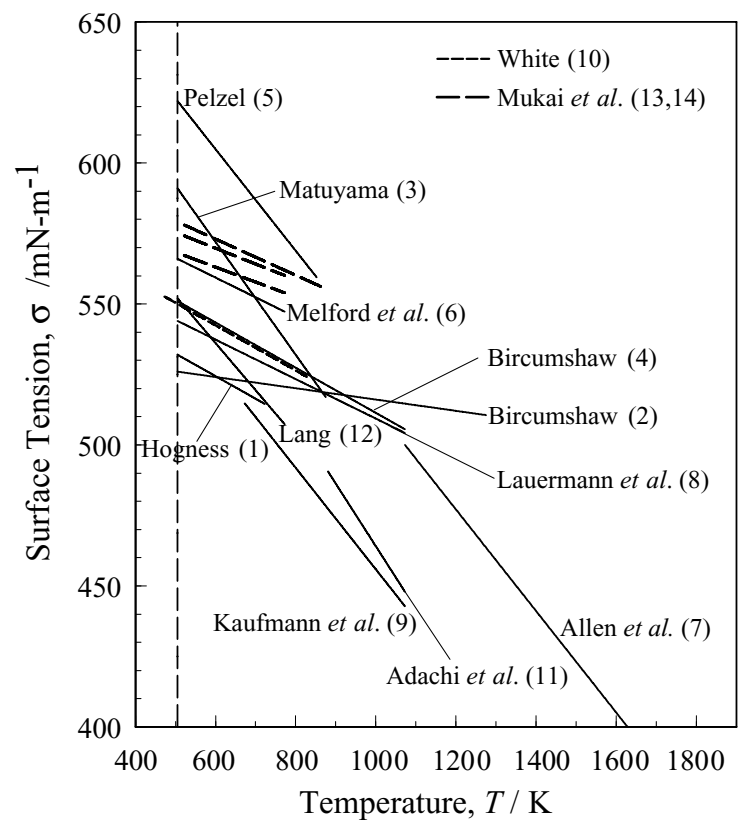

FIG. 4. Surface tension of molten tin reported before 1973. 
TABLE 2

Temperature Coefficients of Surface Tension of Molten Tin Reported by Various Investigators

\begin{tabular}{|c|c|c|c|c|c|c|}
\hline Investigator & Year & Method & Atmosphere & $\begin{array}{l}\text { Surface tension } \\
\text { at } \mathrm{MP}(\mathrm{mN} / \mathrm{m})\end{array}$ & $\begin{array}{l}\text { Temperature } \\
\text { coefficient }\end{array}$ & $\begin{array}{c}\text { Temperature } \\
\text { range }(\mathrm{K})\end{array}$ \\
\hline Hogness (1) & 1921 & MDP & $\mathrm{H}_{2}$ & 532 & -0.08 & $505-723$ \\
\hline Bircumshaw (2) & 1926 & MBP & $\mathrm{H}_{2}$ & 526 & -0.02 & $505-1273$ \\
\hline Matuyama (3) & 1927 & DW & Vac. & 591 & -0.20 & $505-873$ \\
\hline Bircumshaw (4) & 1934 & MBP & $\mathrm{H}_{2}$ & 551 & -0.08 & $505-1073$ \\
\hline Pelzel (5) & 1948 & MBP & $\mathrm{N}_{2}$ & 622 & -0.18 & $505-853$ \\
\hline Melford (6) & 1957 & CR & $\mathrm{H}_{2}$ & 566 & -0.07 & $505-773$ \\
\hline Allen (7) & 1959 & SD & $\mathrm{H}_{2}$ & 500 (at $1073 \mathrm{~K}$ ) & -0.18 & $1073-1873$ \\
\hline Lauermann (8) & 1961 & MBP & $\mathrm{H}_{2}$ & 544 & -0.07 & - \\
\hline Kaufmann (9) & 1965 & SD & Vac. $\mathrm{H}_{2}$ & 545 & -0.18 & 673-1073 \\
\hline White (10) & 1971 & SD & Vac. & 550 & -0.080 & $473-833$ \\
\hline Adachi (11) & 1971 & MBP & Ar & 574 & -0.222 & $881-1073$ \\
\hline Lang (12) & 1973 & MBP & $\mathrm{Ar}$ & 552 & -0.167 & $505-773$ \\
\hline \multirow[t]{2}{*}{ Mukai (13) } & 1973 & SD & $\mathrm{H}_{2}$ & 568 & -0.053 & $523-773$ \\
\hline & & SD & $\mathrm{H}_{2}, \mathrm{Ar}$ & 579 & -0.064 & $523-863$ \\
\hline Mukai (14) & 1973 & $\mathrm{CR}$ & $\mathrm{H}_{2}$ & 575 & -0.056 & $523-773$ \\
\hline Hassan (15) & 1975 & MBP & $\mathrm{H}_{2}$ & 524 & -0.073 & $505-973$ \\
\hline Kasama (16) & 1976 & SD & $\mathrm{Ar}, \mathrm{H}_{2}$ & 560 & -0.091 & $505-1723$ \\
\hline Goumiri (17) & 1982 & SD & Ar, Vac. & 613 & -0.17 & $505-873$ \\
\hline Nogi (18) & 1986 & LD & $\mathrm{Ar}, \mathrm{H}_{2}$ & 630 & -0.13 & $1350-1750$ \\
\hline \multirow[t]{2}{*}{ Sangiorgi (19) } & 1988 & SD & Vac. & 598 (at $560 \mathrm{~K}$ ) & A clean surface & - \\
\hline & & SD & Vac. & 535 (at $560 \mathrm{~K}$ ) & Surface rich in $\mathrm{O}$ & - \\
\hline Nogi (20) & 1989 & SD & $\mathrm{Ar}, \mathrm{H}_{2}$ & 551 & -0.09 & $510-1820$ \\
\hline \multirow[t]{3}{*}{ Passerone (21) } & 1990 & SD & $\mathrm{He}$ & $581(470-580)$ & -0.13 & $505-1073$ \\
\hline & & SD & Vac. & 578 & -0.16 & $505-1023$ \\
\hline & & SD & $\mathrm{He}+5 \% \mathrm{H}_{2}$ & 562 & -0.074 & $505-1023$ \\
\hline Taimatsu (22) & 1992 & SD & $\mathrm{Ar}+3 \% \mathrm{H}_{2}$ & 570 & -0.108 & $873-1373$ \\
\hline \multirow[t]{5}{*}{ Friedrichs (23) } & 1995 & MBP & $\mathrm{Ar}$ & 400 (at $573 \mathrm{~K}$ ) & Positive value & - \\
\hline & & & & 410 (at $703 \mathrm{~K}$ ) & & - \\
\hline & & & & 450 (at $723 \mathrm{~K}$ ) & & - \\
\hline & & & & 660 (at $763 \mathrm{~K}$ ) & & - \\
\hline & & & & 570 (at $1013 \mathrm{~K}$ ) & & - \\
\hline Friedrichs (24) & 1997 & MBP & $\mathrm{Ar}$ & 574 & -0.133 & $598-832$ \\
\hline
\end{tabular}

Note. MDP, maximum drop pressure; MBP, maximum bubble pressure; DW, drop weight; CR, capillary rise; SD, sessile drop; LD, levitated drop.

a very big difference (changed in the range of $470-580 \mathrm{mN} / \mathrm{m}$ ) when the atmosphere $\left(\mathrm{He}+5 \% \mathrm{H}_{2}\right)$ was removed, and the influence of oxygen in atmosphere was reported as the cause. By the sessile drop method, Taimatsu and Sangiorgi (22) measured the surface tension of tin at 1073 and $1273 \mathrm{~K}$, and in the atmosphere of $\mathrm{Ar}+3 \% \mathrm{H}_{2}$ (below the saturated oxygen partial pressure), and obtained certain relations between surface tension and oxygen partial pressure. In addition, Ricci et al. (33) stated in detail the theoretical analysis about the influence of oxygen in the atmosphere on the surface tension of molten pure metal.

According to previous results, the surface tension value of tin in the melting point is in the range of $470-630 \mathrm{mN} / \mathrm{m}$, and the temperature coefficient $\partial \sigma / \partial T$ is in the range of -0.02 to -0.22 .

\subsection{Dependence of Surface Tension on the Temperature and Oxygen Partial Pressure}

The dependence of surface tension on the temperature was investigated in the temperature range from 523 to $1023 \mathrm{~K}$, and at oxygen partial pressure in $\mathrm{Ar}$ atmosphere $P_{\mathrm{O}_{2}}$ (average value) $=2.85 \times 10^{-19}, 1.06 \times 10^{-15}, 3.17 \times 10^{-10}$, and $8.56 \times 10^{-6} \mathrm{MPa}$. The results are shown in Fig. 6 .

In the temperature range of $523-1023 \mathrm{~K}$, the oxygen partial pressure is higher than $P_{\mathrm{O}_{2}}$, sat (see Table 1). From Fig. 6, the temperature coefficients $(\partial \sigma / \partial T) P_{\mathrm{O}_{2}}$ at $P_{\mathrm{O}_{2}}=2.85 \times 10^{-19}$ and $1.06 \times 10^{-15} \mathrm{MPa}$ were $-0.151,-0.094 \mathrm{mN} \mathrm{m}^{-1} \mathrm{~K}^{-1}$, respectively, which are in the reported temperature coefficient range $(-0.02$ to -0.22$)$ shown in Table 2 . However, when $P_{\mathrm{O}_{2}}$ is higher than $3.17 \times 10^{-10} \mathrm{MPa}$, the temperature coefficient increases with increasing oxygen partial pressure $P_{\mathrm{O}_{2}}$, and near the melting point (i.e., at the temperature lower than $733 \mathrm{~K}$ ), it is positive instead of negative. That is, the sign of the temperature coefficient changes with the oxygen partial pressure.

The relation of the surface tension and the oxygen partial pressure is shown in Fig. 7, where the dashed lines are calculated by equations in Fig. 6, and the solid lines are observed results. It is obvious that the surface tension decreases with increasing oxygen partial pressure and temperature. That is, the influence of 


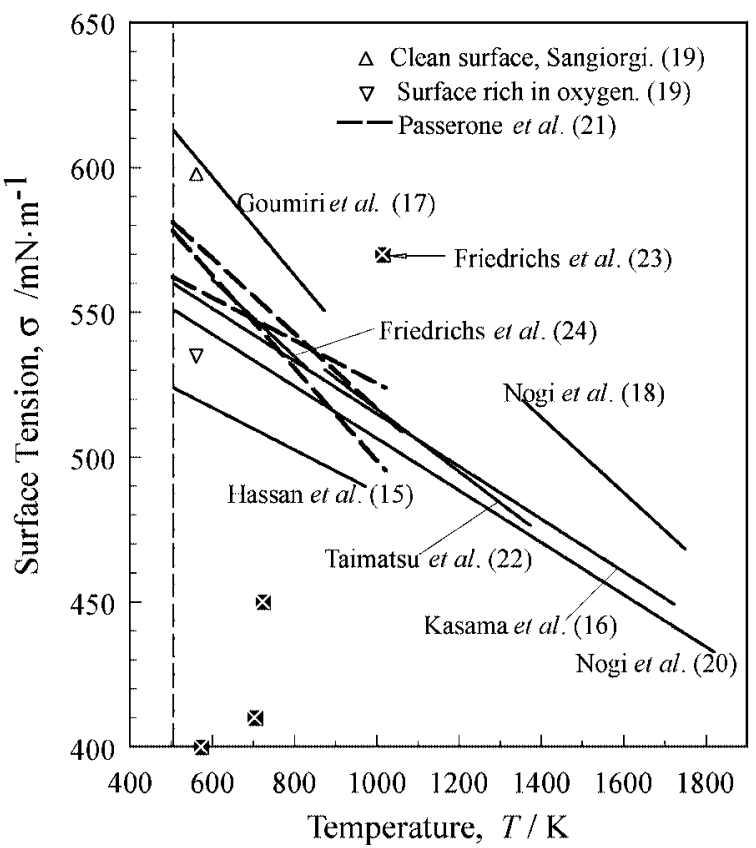

FIG. 5. Surface tension of molten tin reported after 1975.

oxygen partial pressure in Ar atmosphere on the surface tension of molten tin is remarkable at low temperature, but slight at higher temperature.

\subsection{Influence of Oxygen Partial Pressure on the Temperature Coefficient of Surface Tension}

Figure 8 shows the relation between $P_{\mathrm{O}_{2}}\left(\log P_{\mathrm{O}_{2}}\right)$ and the temperature coefficient of surface tension $(\partial \sigma / \partial T) P_{\mathrm{O}_{2}}$ near the

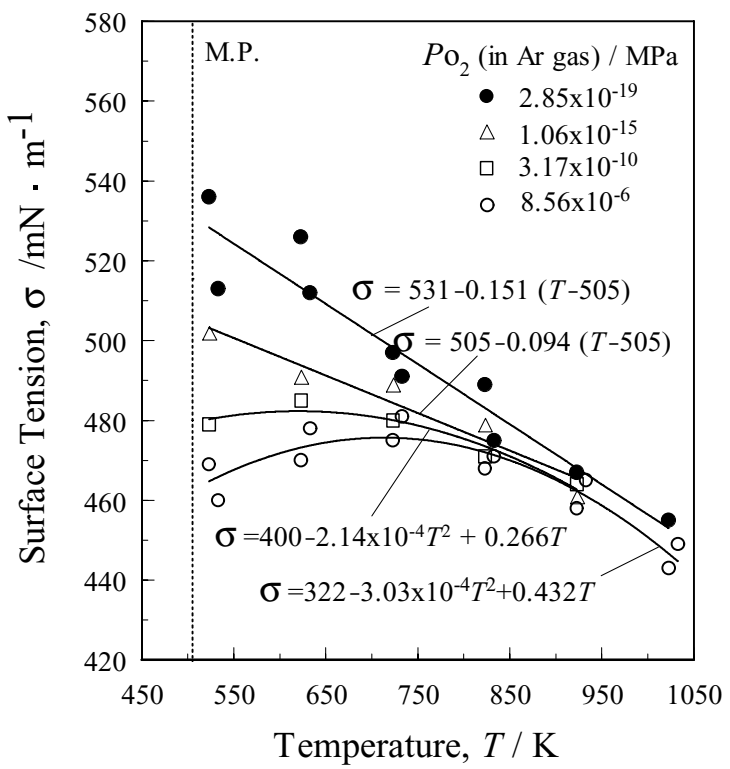

FIG. 6. The surface tension of molten tin in the temperature range from 523 to $1033 \mathrm{~K}$.

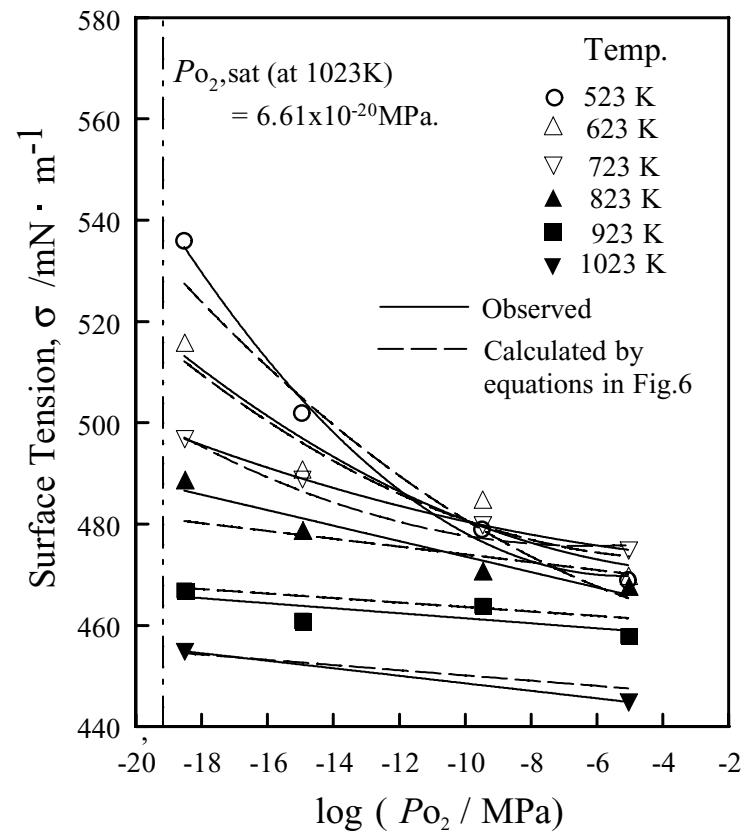

FIG. 7. Relationship between the surface tension of molten tin and the oxygen partial pressure in argon gas.

melting point, which was calculated from Fig. 6. Apparently, $(\partial \sigma / \partial T) P_{\mathrm{O}_{2}}$ increases with increasing $P_{\mathrm{O}_{2}}$, and its value changes from negative to positive near $\log \left(P_{\mathrm{O}_{2}} / \mathrm{MPa}\right)=-9.375$.

As mentioned above, the temperature influence on the surface tension of molten tin changes with $P_{\mathrm{O}_{2}}$. At high $P_{\mathrm{O}_{2}}$, surface tension change with temperature is not linear. The temperature coefficient is positive near the melting point and becomes

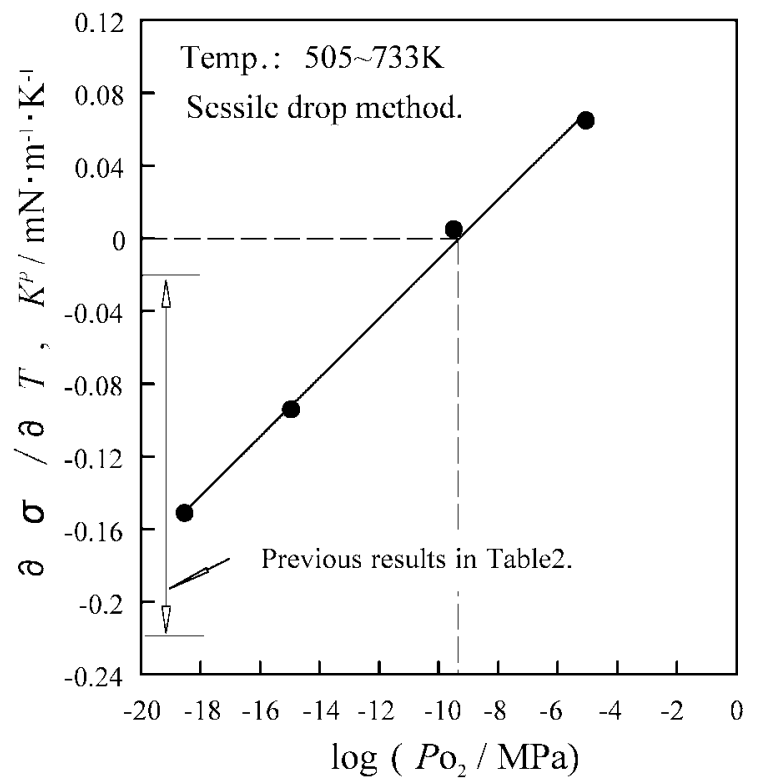

FIG. 8. Temperature coefficient of surface tension of tin changes with the oxygen partial pressure. 


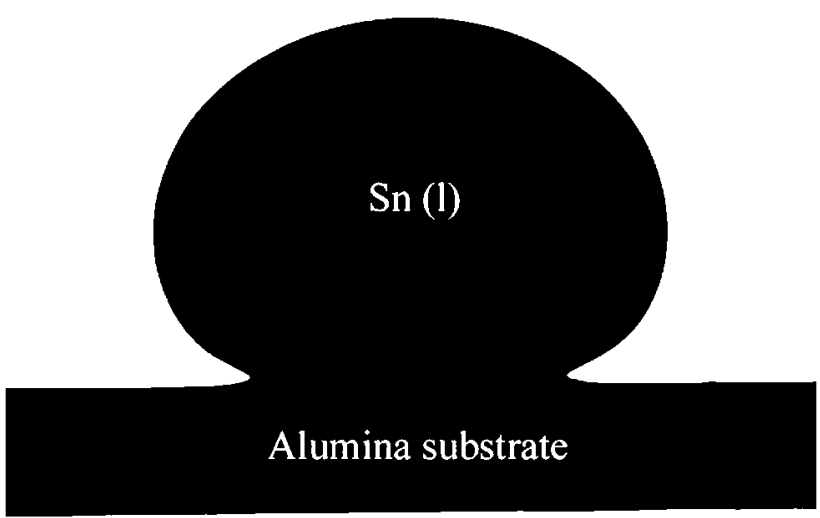

(a) Low $P_{\mathrm{O}_{2}}\left(P_{\mathrm{O}_{2}}=2.85 \times 10^{-19} \mathrm{MPa}\right)$

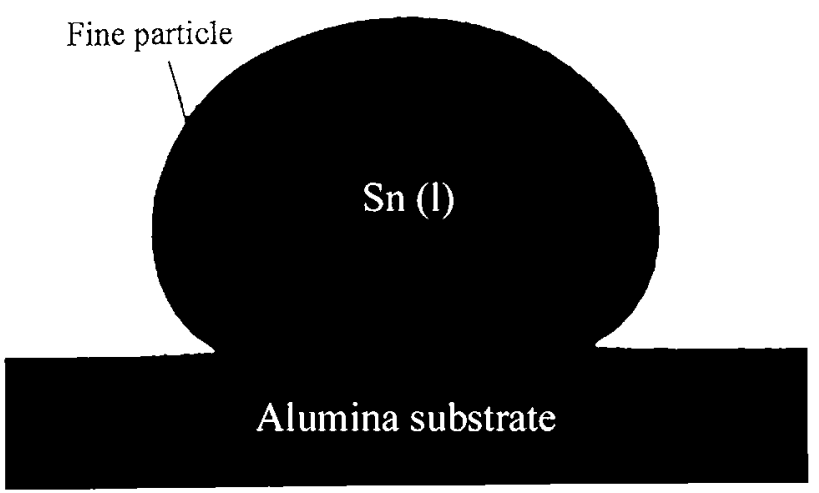

(b) High $P_{\mathrm{o}_{2}}\left(P_{\mathrm{o}_{2}}=8.56 \times 10^{-6} \mathrm{MPa}\right)$

FIG. 9. Tin drop images at $523 \mathrm{~K}$.

negative at about $250 \mathrm{~K}$ over the melting point, as in the case of low $P_{\mathrm{O}_{2}}$.

The same tendency as in Fig. 8 has been found out in molten copper system (34) and molten iron system (35). In addition, Nogi et al. (18) also reported that the temperature coefficients of the surface tension of molten zinc and cadmium were positive above the melting points. White (36) has performed investigation on metals with relatively low melting points, such as In, Cd, and $\mathrm{Zn}$. It showed that the surface tension change with temperature is not linear, and surface atoms order-arrangement (surface ordering) has been observed especially near the melting points. Thus, surface entropy was found to be smaller than that in the liquid bulk, and the temperature coefficients of surface tension were positive.

\subsection{Behavior of Oxygen in Ar Atmosphere and Surface Tension}

As shown in Fig. 6, at low $P_{\mathrm{O}_{2}}\left(2.85 \times 10^{-19}, 1.06 \times\right.$ $10^{-15} \mathrm{MPa}$ ), the surface tension of molten tin decreases monotonically with the increase of temperature, which is similar to the results in $\mathrm{H}_{2}$ atmosphere and many other pure metals. However, if $P_{\mathrm{O}_{2}}$ becomes high, the trend of the temperature coefficient is complicated.

Images of tin drop on printing paper are shown in Fig. 9. Under these experimental conditions, molten tin and the alumina substrate seldom get wet, and the contact angle is $158-173^{\circ}$. The drop surface is smooth at low $P_{\mathrm{O}_{2}}\left(2.85 \times 10^{-19} \mathrm{MPa}, T=\right.$ $523 \mathrm{~K})$. When $P_{\mathrm{O}_{2}}$ is high $\left(8.56 \times 10^{-6} \mathrm{MPa}, T=523 \mathrm{~K}\right)$, fine particles appear on the surface. From surface observation of the sample solidified after measurement, it is found that in the case of high $P_{\mathrm{O}_{2}}$, metal gloss disappears and black brown is presented, while in the case of low $P_{\mathrm{O}_{2}}$, the surface exhibits light gray. Hence, formation of the oxidization film $\left(\mathrm{SnO}, \mathrm{SnO}_{2}\right)$ on the tin drop surface is strongly suggested at high $P_{\mathrm{O}_{2}}$.

Then, as shown in Fig. 10 on the basis of the model proposed by Passerone et al. (21), the experimental results are analyzed from thermodynamics and reaction kinetics.

(a) Conditions where the influence of the measurement atmosphere is strong. In this case, the tin partial pressure $P_{\mathrm{Sn}}$ is relatively low under high $P_{\mathrm{O}_{2}}$ near the melting point of tin, and oxygen arrives at the surface of tin drop easily. And thus, oxidization film is generated. $\longrightarrow$ Oxygen diffusion $\left(\propto D_{\mathrm{O}}\right)$

$\mathrm{O}_{2}$ molecules (proportional to $P_{\mathrm{O} 2}$ ) $\longrightarrow$ Metal vapor diffusion $\left(\propto D_{\mathrm{M}}\right)$

m $= \pm=1 \operatorname{Metal}(\mathrm{Sn})$ vapor $\left(\propto P_{\mathrm{M}}\right)$

$P_{\mathrm{M}}$ : Vapor pressure of metal

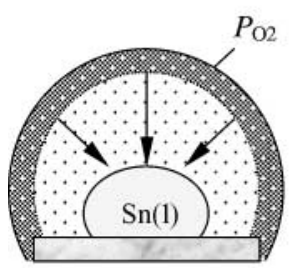

(a)

Fast reaction with excess oxygen

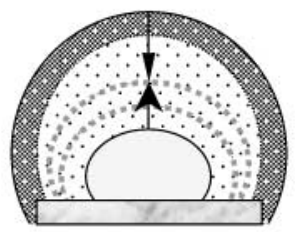

(b)

Transition region from (a) to (c)

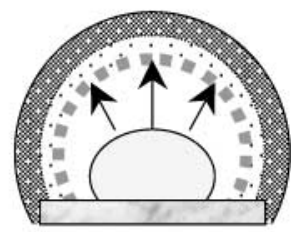

(c)

Fast reaction with metal vapor

FIG. 10. Illustration of the three typical situations near the $\mathrm{Sn}(1)-$ vapor interface. 
(b) Conditions where the influence of the measurement atmosphere is weak. In the atmosphere of low $P_{\mathrm{O}_{2}}$, since the partial pressure of molten tin increases with the increase of temperature, oxygen is caught by $\mathrm{Sn}(\mathrm{g})$ which exists in the drop surroundings, and hence $P_{\mathrm{O}_{2}}$ near the drop surface decreases. Consequently, the reduction rate of surface tension with the $P_{\mathrm{O}_{2}}$ increase is relatively slow.

(c) Conditions where the influence of measurement atmosphere is neglectable. The oxygen concentration in the molten tin that equilibrates the oxygen partial pressure in atmosphere decreases further with the temperature increase, and the amount of adsorption to the molten tin surface also decreases. A "protection layer" of metal steam $\mathrm{Sn}(\mathrm{g})$ is generated around the drop at high temperatures, which plays the role of an oxygen-getter pump, and oxygen diffusion to the molten tin surface is inhibited, with the drop surface maintaining at low oxygen partial pressure.

From Fig. 10, it can be reckoned that the present results have been measured in the conditions from case (a) to case (c). That is, the condition of high $P_{\mathrm{O}_{2}}$ near the melting point belongs to case (a), and in this case oxidization film generates on the drop surface, leading to a low value of surface tension. However, it shifts to case (b) with the $P_{\mathrm{O}_{2}}$ reduction or temperature increase, and the surface tension reduction is inhibited. With further increase of temperature (above $873 \mathrm{~K}$ ) and larger extent of tin vaporization, the oxygen diffusion to the drop surface is almost prevented by the tin vapor atoms, and the surface tension almost has nothing to do with $P_{\mathrm{O}_{2}}$, resulting in a case close to (c). Therefore, maximum values of surface tension are oberved on the curves in Fig. 6 for high $P_{\mathrm{O}_{2}}$ system.

\section{CONCLUSIONS}

The relation between the surface tension of molten tin and the oxygen partial pressure in $\operatorname{Ar}$ atmosphere $\left(P_{\mathrm{O}_{2}}=2.85 \times 10^{-19}\right.$ $\left.8.56 \times 10^{-6} \mathrm{MPa}\right)$ has been investigated in the temperature range from 523 to $1033 \mathrm{~K}$ using the sessile drop method.

(1) At $P_{\mathrm{O}_{2}}=2.85 \times 10^{-19}$ and $1.06 \times 10^{-15} \mathrm{MPa}$, the surface tension decreases linearly with increasing temperature, and negative temperature coefficients $(\partial \sigma / \partial T) P_{\mathrm{O}_{2}}=-0.151$, $-0.094 \mathrm{mN} \mathrm{m}^{-1} \mathrm{~K}^{-1}$ have been obtained, respectively. However, in the case of $P_{\mathrm{O}_{2}}=3.17 \times 10^{-10}$ and $8.56 \times 10^{-6} \mathrm{MPa}$, the surface tension changes nonlinearly with the temperature and increases near the melting point. At $250 \mathrm{~K}$ above the melting point, negative temperature coefficient exhibits as in the case of low $P_{\mathrm{O}_{2}}$.

(2) The $P_{\mathrm{O}_{2}}$ influence on the surface tension of molten tin is remarkable at low temperature, and the surface tension decrease with the $P_{\mathrm{O}_{2}}$ increase becomes very slight at high temperature.
(3) The effect of oxygen in the atmosphere is considered from thermodynamics and kinetics on the basis of a model, and the experimental results can be explained qualitatively.

(4) The contact angle between the molten tin and the alumina substrate is $158-173^{\circ}$, and the wettability is poor.

\section{REFERENCES}

1. Hogness, T. R., J. Am. Chem. Soc. 43, 1621 (1921).

2. Bircumshaw, L. L., Philos. Mag. 2, 341 (1926).

3. Matuyama, Y., Sci. Rep. Tohoku Univ. 16, 555 (1927).

4. Bircumshaw, L. L., Philos. Mag. 17, 181 (1934).

5. Pelzel, E., Berg Huettenmann. Monatsh. Montan. Hochscule Leoben 93, 248 (1948).

6. Melford, D. A., and Hoar, T. P., J. Inst. Met. 85, 197 (1956-1957).

7. Allen, B. C., and Kingery, W. D., Trans. Met. Soc. AIME 215, 30 (1959).

8. Lauermann, I., Metzger, G., and Sauerwald, F., Z. Phys. Chem. 216, 43 (1961).

9. Kaufmann, S. M., and Whalen, T. J., Acta Metall. 13, 797 (1965).

10. White, D. W. G., Met. Trans. 2, 3067 (1971).

11. Adachi, A., Morita, Z., Kita, Y., Kasama, A., and Hamamatsu, S., J. Jpn. Inst. Met. 35, 1188 (1971).

12. Lang, G., J. Inst. Met. 101, 300 (1973).

13. Mukai, K., Kashiwagi, I., and Takanori, T., Res. Rep. Kyushu Technol. Inst. 26, 155 (1973)

14. Mukai, K., J. Jpn. Inst. Met. 37, 482 (1973).

15. Abol-Hassan, K., Abdel-Aziz, Kirshah, M. B., and Aref, A. M., Z. Met. 66, 183 (1975).

16. Kasama, A., Iida, T., and Morata, Z., J. Jpn. Inst. Met. 37, 1030 (1976).

17. Goumiri, L., and Joud, J. C., Acta Met. 30, 1397 (1982).

18. Nogi, K., Ogino, K., McLean, A., and Miller, W. A., Met. Trans. 17B, 163 (1986).

19. Sangiorgi, R., Senillou, C., and Joud, J. C., Surf. Sci. 202, 509(1988).

20. Nogi, K., Oishi, K., and Ogino, K., Mater. Trans. JIM 30, 137 (1989).

21. Passerone, A., Ricci, E., and Sangiorgi, R., J. Mater. Sci. 25, 4266 (1990).

22. Taimatsu, H., and Sangiorgi, R., Surf. Sci. 261, 375 (1992).

23. Friedrichs, H. A., Ronkow, L. W., Vermot, P., and Bliznjukow, S., Steel Res. 66, 509 (1995).

24. Friedrichs, H. A., Ronkow, L. W., and Zhou, Y., Steel Res. 68, 209 (1997).

25. Rotenberg, Y., Boruvka, L., and Neumann, A. W., J. Colloid Interface Sci. 93, 169 (1983)

26. Mukai, K., and Yuan, Z., Mater. Trans. JIM 41, 331 (2000).

27. Lucas, L. D., Mem. Sci. Rev. Met. 69, 395 (1972).

28. Patterson, J., Bogren, E., and Rapp, R., J. Electrochem. Soc. 114, 752 (1967).

29. Yuan, Z., Mukai, K., and Huang, W., Langmuir 18, 2054 (2002).

30. Kubaschewiki, O., and Alcock, C. B., "Metallurgical Thermochemistry," 5th ed. Pergamon, New York, 1985.

31. Amal, T., Hasouna, A., Nogi, K., and Ogino, K., Trans. Jpn. Inst. Met. 29, 748 (1988).

32. Otsuka, S., and Kozuka, Z., Trans. Jpn. Inst. Met. 22, 558 (1981).

33. Ricci, E., Passerone, A., and Joud, J. C., Surf. Sci. 206, 533 (1988).

34. Morita, Z., and Kasama, A., J. Jpn. Inst. Met. 40, 787 (1976).

35. Takiuke, N., Taniguchi, T., Tanaka, Y., Shinozaki, N., and Mukai, K., J. Jpn. Inst. Met. 55, 180 (1991).

36. White, D. W. G., Met. Trans. 3, 1933 (1972). 